\title{
Historia y crítica de la Pedagogía
}

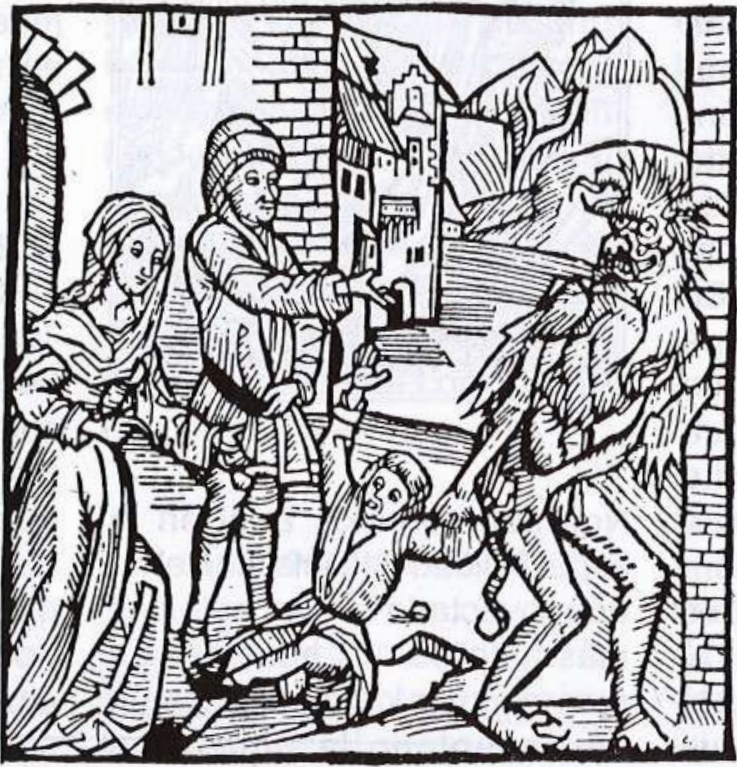

\section{LAS COMPRENSIONES DEL CURRICULO DE PREESCOLAR, VISTAS A TRAVES DEL TRABAJO DE AULA ${ }^{(1)}$}

MARTHA LEONOR SIERRA AVILA Profesora Facultad de Educación Universidad Pedagógica Nacional

\section{INTRODUCCION}

El presente escrito pretende mirar las distintas maneras como se concreta en la práctica el currículo de Preescolar,

Ponencia presentada al II CONGRESO PEDAGOGICO NACIONAL. Bogotá, Noviembre de 1994. señalando cómo el trabajo de aula tiene muchas veces caminos y sentidos diferentes a los planteados desde instancias formales del Ministerio de Educación MEN, ya sea a través de Leyes, Resoluciones o Planteamientos Curriculares.
Reflexionar acerca del curriculo de Preescolar, sus concepciones, principios, relaciones, estrategias, resulta pertinente en un momento en el que las comunidades educativas se cuestionan por su participación en el diseño, ejecución y eva- 
luación de los Proyectos Educativos institucionales PEI.

El proceso de búsqueda de alternativas de salida a la crisis de la escuela, no inicia ahora; la dinámica de maestros innovadores nos permitió, años atrás, preguntarnos por los Proyectos Pedagógicos. Igualmente, en la DIE-CEP $\left(^{*}\right)$ desde 1988 se impulsó, a través de los procesos de formación docente, la construcción de PEI. En este momento, el MEN avanza en la definición y legalización de esta propuesta (Ley 115) que de manera importante, afecta los desarrollos pedagógicos de las instituciones. Independiente de la Ley, todos los maestros tenemos la responsabilidad y el compromiso de contribuir en la cualificación de nuestras instituciones.

Lo anterior nos coloca en un lado de la balanza del trabajo pedagógico, cual es la relación con lo macro, expresada en la búsqueda de una intencionalidad y una identidad institucional; pero nos abre un interrogante al colocarnos al otro lado de la balanza en su relación con lo micro, como es la especificidad del trabajo de aula. Es importante empezar a cuestionarnos por la articulación del PEI. con el Proyecto de Aula y continuar avanzando simultáneamente en ambos.

\footnotetext{
* Dirección de Investigación para la Educación - Centro Experimental Piloto de Bogotá.
}

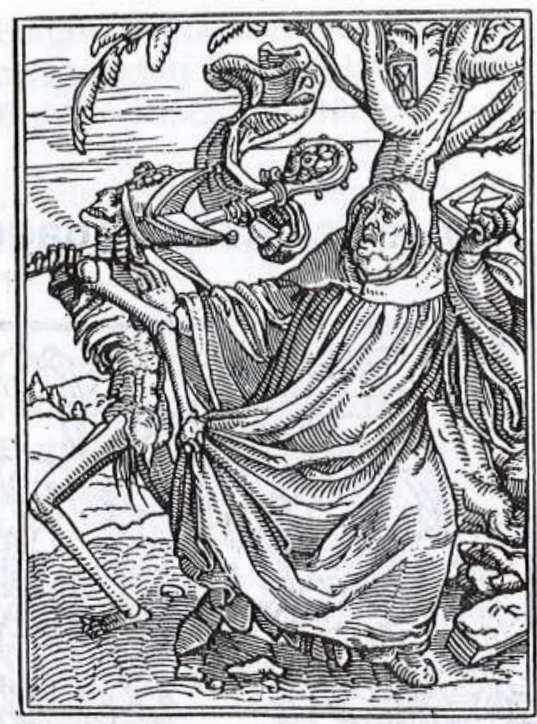

Nos detendremos aqui en la especificidad del aula, con el fin de proyectarla hacia contextos más amplios. Si hacemos un recorrido por los principios que han orientado la Educación Preescolar, vemos cómo han sido planteamientos constantes el desarrollo de la Autonomía, el desarrollo Integral, la Adecuación al Contexto y el Respeto por los Intereses de los Niños. Sin embargo, durante varias décadas ha prevalecido, en la práctica, un trabajo centrado en el desarrollo de conductas, habilidades y destrezas, expresado en un marcado carácter funcional de las acciones del aula.

Acerquémonos a las formas de trabajo más difundidas, que no sólo han existido, sino que aún existen en Preescolar, y más aún, muchas veces coexisten de manera yuxtapuesta en una misma aula. No nos asiste el ánimo de criticar, sino el de des- cubrir lo hecho o dejado de hacer en el campo particular del currículo, entre otras cosas porque si no existen en Colombia propuestas más acordes con lo que sentimos o pensamos, de alguna manera es porque los maestros han estado ausentes en la construcción de lo que hoy existe.

\section{ENFOQUES CURRICULARES}

Los diferentes enfoques curriculares han dependido del momento político por el que atraviese el pais, de unos intereses de tipo económico y sociales, que conllevan concepciones de hombre, educación, cultura, etc., independientes de los desarrollos mundiales de la ciencia y la tecnología.

En Colombia, a partir de la década del 70 , se ha insistido en la implementación de propuestas de la psicología cognitiva, sin tomar conciencia, quizás, de que el fondo de la discusión entre "procesos» y "resultados» se encuentra soportado por intereses de tipo social, lo cual opone en muchos de los casos la búsqueda de significación a la eficiencia, el desarrollo de estructuras lógicas a respuestas correctas.

De esta manera, cada momento vivido en la implementación de propuestas pedagógicas en Preescolar, no obedece sólo a las comprensiones del maestro, sino también a los desarrollos 
mismos de las ciencias y el pais. Es necesario señalar como la Psicología es la que más influencia ha ejercido sobre la Pedagogía, fluctuando entre comprensiones y manejos de la Psicología Conductual, la Psicologia Genética, la Psicología del Aprendizaje y la Psicología Cognitiva.

En Preescolar ha prevalecido un enfoque curricular de carácter conductual, evidenciado en prácticas centradas en el Aprestamiento y en el diseño de la tecnologia educativa.

\subsection{Aprestamiento}

El aprestamiento se plantea como una práctica que hace énfasis en el desarrollo de habilidades y destrezas de coordinación fina (recortar, picar, rasgar, pegar), consideradas prerrequisitos para el aprendizaje de la escritura; como si escribir fuera fundamentalmente un acto motor, y no un proceso de esencia cognitiva y lingüística.

La discriminación de formas, tamaños y colores, también se postula como prerrequisito para la matemática; como si la problemática implicada en este tipo de conocimiento fuera de tipo perceptual y no de estructuras lógicas. Esto conlleva a que los conceptos se trabajen aisladamente y de manera mecánica, sin significado para el niño. Un día el mundo del aula se vuelve de color rojo: se pica sobre lo rojo, se colorea de rojo, se recorta lo rojo. Otro día, se vuelve azul o de forma de círculo, o de triángulo...

No es que en Preescolar no se deba colorear o moldear con plastilina, o que no se desarrolle la coordinación visomotriz; es que debe dársele una orientación diferente, no como un aprendizaje previo, sino vinculado a actividades plenas de significación individual y colectiva, con una intención comunicativa y ligada a construcciones conceptuales.

\subsection{Tecnología educativa}

Otra propuesta curricular asumida por Preescolar es la planteada desde el enfoque de la tecnología educativa, en la Renovación Curricular; de ésta es necesario rescatar algunos aspectos esenciales que superan la práctica centrada en el Aprestamiento, aunque se reconoce que tiene contradicciones y vacíos.

Como positivo se plantea:

La concepción de niño como alguien que llega al jardín con conocimientos y formas de relación con el mundo,no como un ser vacío que debe ser llenado de información.

- La concepción de currículo en términos de un proceso de planeación, desarrollo y evaluación de eventos significativos, y no como un listado de temáticas o de actividades.

- La intención de favorecer la búsqueda de múltiples alternativas pedagógicas que respondan a los contextos específicos en los cuales se réaliza el quehacer del maestro.

Sin embargo, estos principios se contradicen en los siguientes aspectos:

- En la delimitación del currículo en áreas de desarrollo, contenidos y estrategias curriculares, donde se aprecia una concepción de niño, no como ser integral, sino como resultado de un conjunto de áreas de desarrollo: percepción, motricidad, lenguaje, afectividad, inteligencia, creatividad, las cuales a su vez son definidas en términos de comportamientos.

- En la atomización que se hace del conocimiento desde la

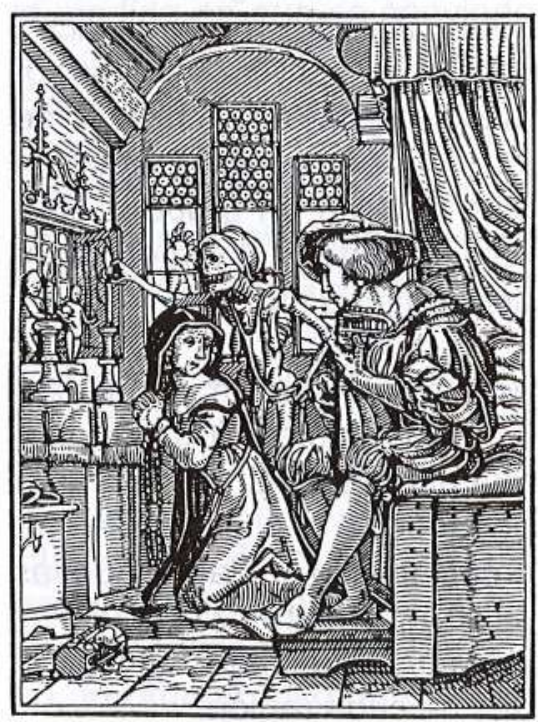


organización académica tradicional por materias: ciencias naturales, ciencias sociales, educación estética, educación religiosa, sexual, vial, para la salud, pre-lectoescritura y pre-matemática.

- En el planteamiento de las estrategias curriculares (juego libre, actividades en grupo, unidad y trabajo con padres de familia) como independientes una de otra, con asignación en el horario, duración, funciones y metodología específicas.

La implementación, en la práctica, arrojó otra serie de dificultades:

Las unidades se transformaron en programa, en un listado de temas que cumplir, tales como: mi cuerpo, mi colegio, mi familia, los medios de comunicación, los medios de transporte, los animales, los alimentos, la navidad; no obstante haber planteado el currículo que la Unidad debía surgir de los intereses, necesidades y caracteristicas de los niños y/o la comunidad educativa; en razón de lo cual nunca habría una Unidad igual de un grupo a otro, de un jardín a otro $y$, menos, de una región a otra.

Ante esta situación, es inevitable la pregunta por la Autonomía del maestro, por su saber pedagógico y su capacidad de crear, no sólo unidades nuevas sino propuestas curriculares que respondan a las necesidades de cada región.

\subsection{Espontaneismo}

Una forma particular de organización de las acciones del aula, es la caracterizada por una práctica que pretende basarse en los principios de la lúdica y de los centros de interés, pero que en su concresión pedagógica cotidiana se convierte en una práctica espontaneista, dado que cada día se espera que surja un nuevo interés sobre el cual trabajar, ya sea éste la mariposa que entró al aula, el pajarito que se murió o el nacimiento de un hermano.

Cada tema se trabaja de manera independiente, sin un eje que los articule. El surgimiento de los mismos es coyuntural y su desarrollo asistemático. No hay secuencia en los procesos, ni se proyectan acciones a largo plazo.

Esta intención frente a lúdica se convierte en un elemento que oculta la falta de sistematicidad, ya que los niños "la pasan bien», pintando, cantando, jugando con plastilina o bailando. Los intereses de los niños se reducen y el papel del maestro en el aula se minimiza.

\subsection{Constructivismo}

Como un momento importante en el desarrollo curricular, a partir de 1992 surge desde el MEN una nueva propuesta pedagógica que se convierte en elemento de tensión respecto a las mencionadas maneras de concebir la práctica en Preescolar. Esta es la propuesta pedagógica de Grado Cero. Si bien es cierto que surge dentro del marco de las políticas neoliberales, permite:

- Mirada críticamente las concepciones de niño, maestro, escuela, aprendizaje, que se ponen de manifiesto en el acto pedagógico.

- Romper esquemas rutinarios de propiciar el acercamiento al conocimiento de la lectura, la escritura y la matemática.

- Superar la visión atomizada y academicista del desarrollo del niño y de su aprendizaje.

- Resaltar la actividad reflexiva e interiorizada, producto de la interacción con el mundo físico y social como la principal forma de construcción de conocimiento, y a su vez, destacar como dos formas de esta actividad el juego y la comunicación.

- Plantear elProyecto como la estrategia principal para buscar de soluciones a problemas y preguntas que surgen del entorno y la cultura de la cual el grupo y la maestra hacen parte, al tiempo que brinda elementos conceptuales muy amplios y flexibles alrededor de la planeación,la organización y la evaluación.

Podriamos decir que esta flexibilidad y amplitud ha permitido a las diferentes regiones reali- 
zar sus propias elaboraciones curriculares, pero en muchos de los casos el maestro ha asumido el cambio sólo desde las metodologias de la lectura, la escritura y la matemática, concibiendo los proyectos sólo como una estrategia o forma de trabajo, poniéndose una vez más en evidencia una concepción de indole instrumental, que señala implicaciones sustanciales para nuestra tarea de formación de maestros, así como para el tipo de proyectos educativos en los cuales nos comprometemos.

No es suficiente que las propuestas "curriculares se transformen, o que se realicen esfuerzos en términos de definición de políticas educativas, leyes, resoluciones o programas, sino que se deben crear todas las condiciones necesarias que posibiliten el papel de los maestros en las definiciones curriculares y el papel de las comunidades en la delimitación de prioridades. Se hace necesario, igualmente, entender que una ley es el resultado de acuerdos y compromisos, pero no el punto final de una búsqueda, y que como tal, debe ser leída e interpretada para encontrar nuevas respuestas, desde la pedagogia, a los interrogantes que la sociedad actual le hace a la escuela.

Por otra parte, las propuestas curriculares han surgido con una intención transformadora, pero sin tener en cuenta las preguntas, avances, dificultades, concepciones y prácticas cotidianas de los maestros, lo cual ha conllevado a una falta de apropiación por parte de los mismos y, por ende, a una yuxtaposición de enfoques y modelos.

Superar este entrecruzamiento de enfoques y modelos implica:

- Asumir que el maestro es responsable de su quehacer, lo cual no significa ser administrador de currículo o bien ejecutor de prácticas.

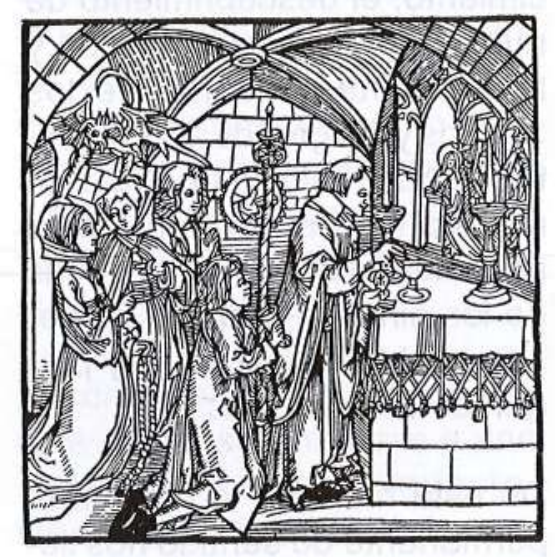

- Comprender que un cambio de actitud no es sólo un acto de buena voluntad de los maestros, considerados individualmente, sino que es un asunto que compromete a los colectivos docentes que hacen de la reflexión sobre la práctica pedagógica una primera actitud y una constante que sienta bases, para que la conciencia del tradicionalismo pedagógico dé paso a la experimentación de innovaciones.
- Realizar una lectura crítica de la Ley General de Educación, ya que los objetivos específicos que establece para la Educación Preescolar, también entrecruza concepciones frente al desarrollo del niño. Asi, por ejemplo, aparecen de manera yuxtapuesta: la motricidad, el aprestamiento y la motivación para la lectoescritura; la formación de hábitos y la generación de conciencia; la estructuración espaciotemporal y el ejercicio de la memoria.

\section{UNA MIRADA ALTERNATIVA}

El problema del Preescolar no es, pues, de formulación de objetivos, o de nuevas metodologías y estrategias. Una transformación de calidad exige una visión totalizadora de la acción pedagógica y de la formación docente.

EI Preescolar debe asumirse a si mismo como un Proyecto, en la medida en que se convierte en un proceso en permanente construcción, que abre espacios de participación y reflexión a niños, padres, maestros y comunidad, que establece nuevas formas de relación entre los sujetos y de éstos con el conocimiento y la cultura, a través de una búsqueda sistemática de sentido.

El PEl y el Proyecto de Aula, están unidos por una misma intencionalidad en lo pedagógi$\mathrm{co}$, lo organizativo, lo cultural, 
pero particularizados en lo referente a la relación con el conocimiento. Desde esta perspectiva, no podemos pensar los Proyectos en Preescolar como una estrategia, sino como una forma diferente de mirar lo escolar, tanto en lo pedagógico, como en lo organizativo, lo éti$\mathrm{co}$, lo lúdico, lo comunicativo y lo comunitario. Exige, a la vez, mirar lo escolar más allá del aula, puesto que abarca una red de interrelaciones sociales, educativas y culturales, que exigen la vinculación de la comunidad y otras instituciones, demandando la capacidad protagónica de todos los sujetos involucrados, a través de un proceso conciente, sistemático y participativo.

Lo anterior no implica que el Proyecto de Aula del Preescolar se diluya en lo comunitario o en lo institucional, o que se convierta la intención institucional en un agregado más del aula. Asi, por ejemplo, el que una institución defina como PEI "La Escuela: Un Espacio para el Ejercicio de la Democracia», dadas sus propias necesidades y características, no significa que en Preescolar, o en cualquier grado, se deje de lado el conocimiento matemático, o el conocimiento físico, o la interacción. El esfuerzo está en articular lo general con lo específico, lo macro con lo micro.

El Proyecto de Aula debe entonces, vincularse con esos aspectos macro, pero responder y concretarse en la especi- ficidad del aula. Surgir en y para los contextos familiar, escolar y barrial, pero proyectarse y repensarse desde contextos más universales (nacional e internacional).

El Proyecto de Aula exige una visión holística y dinámica del Ser, que enriquezca los espacios de socialización en los que las relaciones consigo mismo, con el mundo físico, ético y estético, son a la vez un eje articulador y un horizonte de búsqueda, que posibilite nuevas formas de acceso al conocimiento, el descubrimiento de nuevas formas de expresión y la autodeterminación de los Sujetos y los grupos. EIProyecto de Aula tiene una doble dimensión: Una, los intereses, necesidades y características de los niños, y otra, los intereses, problematizaciones y preguntas del maestro.

De esta manera, la búsqueda permanente de sentido nos lleva a establecer múltiples relaciones, construyendo una visión de mundo cada vez más amplia y profunda, tocándose en unos momentos, fijando linderos en otros y muchas veces abriéndose porque las preguntas y preocupaciones de los niños no son las mismas que las del maestro.

A partir de los intereses de los niños, surgidos en la dinámica de la colectivización de individualidades, se determina un tema eje en torno al cual establecen relaciones retomando los conocimientos que ya poseen. Es tarea del maestro interpretar estas múltiples relaciones que los niños establecen para ayudar a ampliarlas y profundizarlas.

EI Proyecto de Aula integra así el colectivo, respetando los ritmos individuales a través de acciones articuladas por un eje significativo común que compromete y afecta en su Ser a todos los sujetos que interactúan. Pueden existir subproyectos que permitan crear diferentes dimensiones de apropiación, pero siempre mirado como una totalidad articulada, constituida por una red de interrelaciones que no deje por fuera lo científico, ni lo artístico, ni lo ético, ni lo mágico e imaginativo.

Lo anterior va más allá de concebir el aprendizaje como una simple adición o acumulación de nuevos elementos a la estructura cognitiva del niño, o de pretender una articulación de las disciplinas, o los temas, de la forma más sencilla a la más compleja. El tema o problema que se aborde debe responder a las necesidades de relación que los niños van estableciendo respecto al conocimiento físico, social, lógico matemático o estético.

De ahi que seguir modelos de concretización curricular que fijen temas, secuencias, tiempos, suele impedir la explicitación de las relaciones que los niños establecen, por lo cual se de- 
manda de los maestros una mayor apertura en la planificación de las acciones y mayor flexibilidad interpretativa en el momento de su puesta en marcha.

Participar en el Proyecto de Aula exige una mirada, integral del proceso de aprendizaje, en el que los contenidos se manejan flexible y fluidamente, lo que no permite que exista un esquema tipo que defina pasos y temas parcelados desde el inicio del año escolar.

Definir el eje temático del proyecto implica un acercamiento permanente a cada niño en particular y al grupo en general, para identificar sus intereses, necesidades y características de desarrollo, desde la comprensión de su entorno social, sus formas de interacción, sus maneras de expresarse, de solucionar conflictos, sus maneras de explorar lo que les atrae, etc.

Lo anterior sólo es posible si el maestro se abre a los niños, flexibiliza su pensar, sentir y actuar, reduce su poder como adulto y fluye con el grupo. De esta manera "descubrirá» y "vivirá» con los niños su interés por el mar, el espacio, los aviones, los dinosaurios o el circo. Sabrá en su momento oportuno cuál es el tema que les apasiona.

Detectar los intereses de los niños no significa esperar a que todo el grupo se encuentre motivado, ya que su papel está en colectivizar individualidades. Tampoco significa que debe esperar con paciencia a que surjan espontáneamente, puesto que se pueden suscitar situaciones que posibiliten a los niños expresen sus gustos, temores, creencias, necesidades y problemas.

El desarrollo de experiencias 'inestructurada, como puede ser el tener adecuado el salón con cajas y sábanas para que los niños jueguen, pudiéndonos mostrar su interés por los barcos, las casas, los fantasmas o la ciudad, etc., puede ser, entre otras, una estrategia para detectar intereses, como también lo es la observación de sus juegos, la atención a sus conversaciones o la valoración de sus "corrillos».

Encontrar el eje temático le permite al maestro hacerse a una idea macro del Proyecto, visualizar acciones, imaginar un camino, crear condiciones, presentar opciones, etc., pero sólo el grupo es quien le imprime una dinámica, un recorrido $y$ una finalidad particular, exigiéndole al maestro aprender a vivir lo inesperado.

La búsqueda permanente de sentido permite que las acciones no sean simplemente coyunturales y desarticuladas, sino que lleva a establecer múltiples relaciones y a construir nuevos significados. Así, el eje temático se amplia en unos momentos, tocándose con

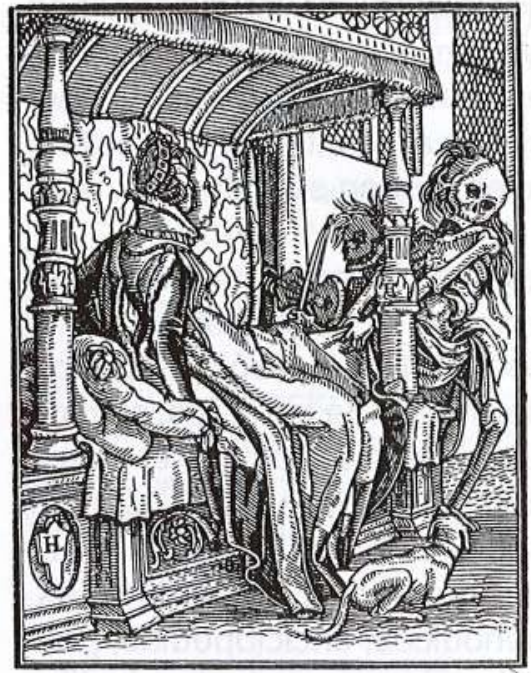

otros temas e intereses; profundiza en un tema dando lugar a un proceso de carácter investigativo; y se subdivide, en otros, conduciendo al desarrollo de subproyectos.

En el desarrollo del Proyecto de la profesora Otilia Galeano (Centro Educativo Distrital Rodrigo Lara Bonilla), la temática central era "el mar», pero en torno a él se desarrollaron temas de los piratas, los barcos, los animales del mar, las plantas, la pesca, la contaminación, etc.

El eje del Proyecto no puede constituirse en una "camisa de fuerza», donde necesariamente convergen todas las acciones de la institución (izadas de bandera, dia de la familia, festivales, etc.). Algunas veces estas acciones se podrán articular, otras se realizarán paralelamente y en otras ocasiones se suspenderá momentáneamente el Proyecto. Lo importante es 
que exista una intencionalidad común que oriente el proceso escolar, de manera que las acciones aparentemente coyunturales tengan sentido.

La posibilidad de ampliar y relacionar el tema eje con otros contenidos, no sólo depende del interés de los niños, sino de la documentación que el maestro haga del mismo, al estudiar sobre el tema, buscar diferentes materiales como revistas, periódicos, enciclopedias, películas; hacer contactos institucionales para el acceso a sitios especiales; realizar contactos con personas que saben del tema o han vivido experiencias relacionadas con él, con el fin de hacerse a un abanico de posibilidades, para que los niños opten por ellos en un momento dado.

Las acciones del Proyecto deben materializarse en hechos plenos de significación, que recojan procesos desarrollados. Son ejemplos de esta materialización un mural que se elabore con los niños, poco a poco; en la medida en que se hacen

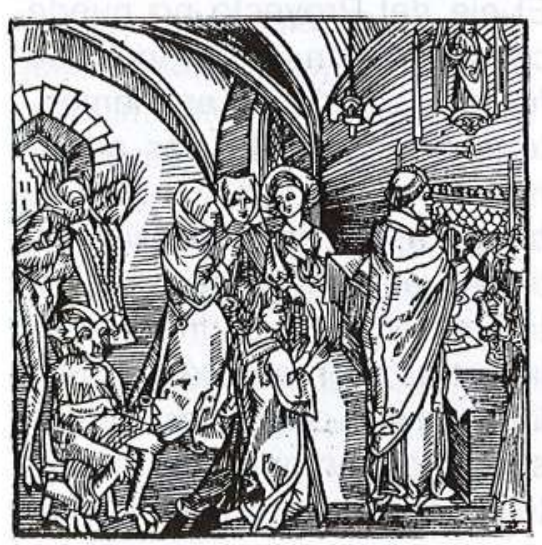

elaboraciones conceptuales, recreándose en él, de manera plástica, el proceso vivido. O el libro de cuentos ilustrados, que sistematiza las producciones de los niños. O la maqueta que muestra las comprensiones del espacio.

Bajo la concepción de Proyecto de Aula, la práctica del maestro se convierte en una acción reflexionada, que permite la pregunta sistemática por su sentido y crea condiciones para la investigación en el aula, a través de la recuperación crítica de los procesos vividos, su análisis y confrontación conceptual.

Se resalta aqui el quehacer del maestro como una práctica-reflexionada, que tiene como resultante nuevas comprensiones sobre lo pedagógico, lo educativo y lo cultural, surgidas del debate y la confrontación con los otros. Los esfuerzos individuales deben ir articulados a una búsqueda común de toda la institución.

Si el Proyecto de Aula no genera confrontación o contradicción con ese saber espontáneo y cotidiano tanto de los niños como de los maestros, no se produciria movilidad de pensamiento, ni se suscitarian nuevas formas de acción. De igual manera, si el Proyecto de Aula no mueve las estructuras de la institución, está condenado a convertirse en una isla.

Lo anterior implica concebir la formación de maestros dentro de una perspectiva diferente, para el ejercicio autónomo y fundamentalmente ético de su diario transcurrir.

\section{FORMACION DOCENTE}

De manera congruente con los principios anteriores, desde la Universidad Pedagógica Nacional la formación de los docentes de Preescolar se piensa en torno a tres principios orientadores: Construcción de Conocimiento, Autonomia y Creatividad. Para el logro de estos principios, la Licenciatura ha planteado una serie de temáticasproblema que permitan la búsqueda de sentido y la reflexión permanente de su quehacer alrededor de tres ejes:

- Educación y Sociedad, que aborda la determinación sociocultural de los procesos de socialización.

- Pedagogía, que permite la ubicación en la historia de un saber específico, la pregunta por la especificidad de ser maestros, las dimensiones de su práctica y la recontextualización de una disciplina particular.

- Estructuración del Sujeto, que permite avanzar en la concepción de lo humano y de la infancia en particular.

Se piensa como fundamental la posibilidad que el maestro tenga de mirarse, de reconocer las imágenes que tiene de sí, de 
valorar sus posibilidades de sentir, de transformar y expresar, asi como de generar procesos de reflexión sistemática.

La formación teórica y práctica de los futuros docentes se realiza a través de Proyectos $\mathrm{Pe}$ dagógicos, orientados a responder las demandas del contexto social.

La educación de educadores se entiende como un proceso de formación de agentes transformadores de la realidad, con la convicción de que la realidad sólo se conoce participando activamente en ella y en una confrontąción permanente de la teoria y la práctica.

Se pretende construir una nueva valoración del quehacer del maestro, formándolo para que asuma su práctica con un carácter investigativo, de reflexión, sistematización y búsqueda permanente de nuevas significaciones y sentidos.

Se plantea la necesidad de crear condiciones para generar una nueva cultura en torno a la infancia, desde un esfuerzo de carácter interinstitucional, que permita responder a los requerimientos que la sociedad actual le hace a la Escuela.

El compromiso de transformación de la cultura en torno a la Infancia nos compete a todas las instituciones o personas que, de manera directa o indirecta, tenemos que ver con la niñez. Unamos todos nuestros esfuerzos en la construcción de una nueva sociedad. Creemos juntos las condiciones que el pais y el mundo nos exigen. Que el Proyecto Pedagógico se nos convierta en un Proyecto Vital.

\section{BIBLIOGRAFIA}

MEN. Currículo de preescolar para niños de 4 a 6 años. Bogotá, 1978.

\section{MEN. Ley $115 / 94$}

MEN. Procesos de desarrollo y algunos temas relacionados con el preescolar. Bogotá, 1980.

MEN. Propuesta curricular piloto para Grado Cero: Marco político, conceptual y pedagógico. Santafé de Bogotá, 1992.

DIE-CEP. Proyecto pedagógico educativo cultural para Grado Cero. Secretaría de Educación del Distrito. Santafé de Bogotá,1992.

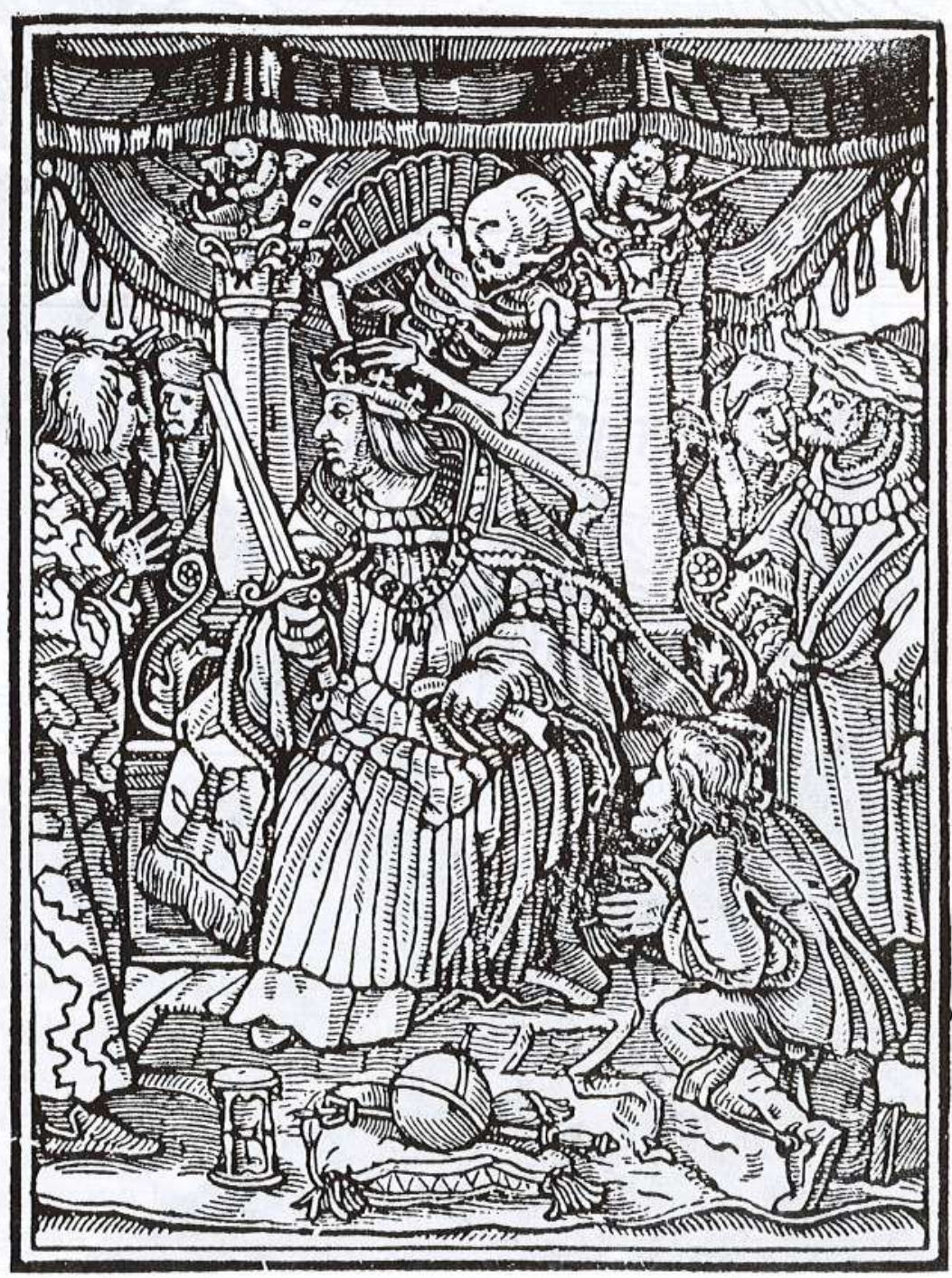




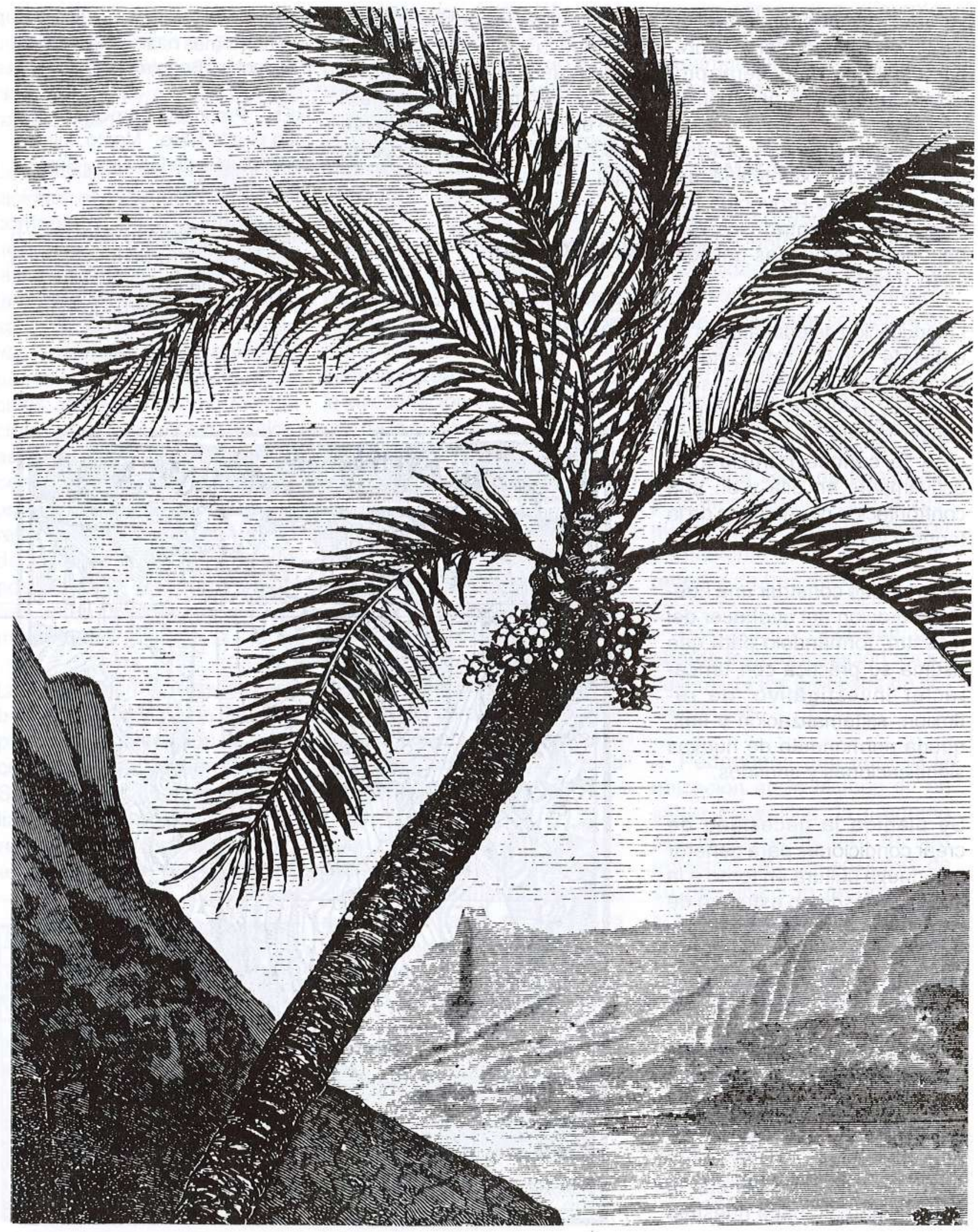

